\title{
Placental Site Nodule (PSN): An Uncommon Diagnosis with a Common Presentation

\author{
Sneha $\mathrm{GS}^{1^{*}}$ and Ramesh Kumar $\mathbf{R}^{2}$
}

${ }^{1}$ Assistant Professor, Department of Obstetrics and Gynaecology, SDM Medical College and Hospital, SDM University, Karnataka, India

${ }^{2}$ Professor, Department of Obstetrics and Gynaecology, SDM Medical College and Hospital, SDM University, Karnataka, India

*Corresponding author: DR. Sneha GS, Assistant Professor, Department of Obstetrics and Gynaecology, SDM Medical College and Hospital, SDM University, 580009, Dharwad, Karnataka, India

\begin{abstract}
Placental site nodule is an uncommon, benign, generally asymptomatic lesion of trophoblastic origin, which may often be detected several months to years after the tenancy from which it resulted. PSN usually presents as menorrhagia, intermenstrual bleeding or an abnormal pap smear. PSN is benign, but it is important to distinguish it from the other benign and malignant lesions like decidua, placental polyp, exaggerated placental site and placental site trophoblastic tumor and squamous cell carcinoma. Follow ups of typical PSNs do not show recurrence or malignant potential. PSN is an uncommon condition which should be suspected in cases of abnormal bleeding, especially following uterine surgical procedures preceding last pregnancy. Timely diagnosis and treatment is necessary to differentiate it from potentially malignant placental lesions with a similar presentation.
\end{abstract}

\section{Introduction}

Placental site nodule (PSN) is a rare, benign lesion which represents remnants of intermediate trophoblast from a previous gestation that has failed to completely involute [1-3]. Although PSN occurs in the reproductive age group, a temporal association with recent pregnan$c y$ is usually lacking and often the time interval between pregnancy and diagnosis of PSN can be several years. These lesions are discovered as incidental findings in curettage or hysterectomy specimens performed for evaluation of irregular uterine bleeding, abnormal cervical smears, post coital bleeding etc. $[1,4,5]$. Infertility is a rare mode of presentation in PSN. PSN needs to be dif- ferentiated from aggressive lesions of intermediate trophoblast like placental site trophoblastic tumor and epithelioid trophoblastic tumor and from nontrophoblastic diseases like squamous cell carcinoma $[1,4]$.

\section{Case Report}

A 29-yrs-old female patient para 3, living 3, abortion 5, underwent laprotomy and tubectomy 2 yrs back presented with history of irregular menstrual cycles with menorrhagia since 6 months preceded by normal cycles. She complained of easy fatigability. She gave a history of undergoing dilatation and curettage after her $5^{\text {th }}$ abortion in view of retained products. Her eighth pregnancy was uneventful and she delivered normally at term. She had puerperal abdominal tubectomy immediately after delivery. One year she had lactational amenorrhea after which she had irregular bleeding with menorrhagia from 6 months.

General physical examination and routine gynaecological checkup were normal, hormonal profile and pap smear were normal serum beta HCG was negative.

She was detected to have Diabetes.

\section{Investigations}

Ultrasonographic evaluation showed thickened endometrium measuring $15 \mathrm{~mm}$ in thickness. Hence patient was advised for dilatation and curettage for further analysis. 


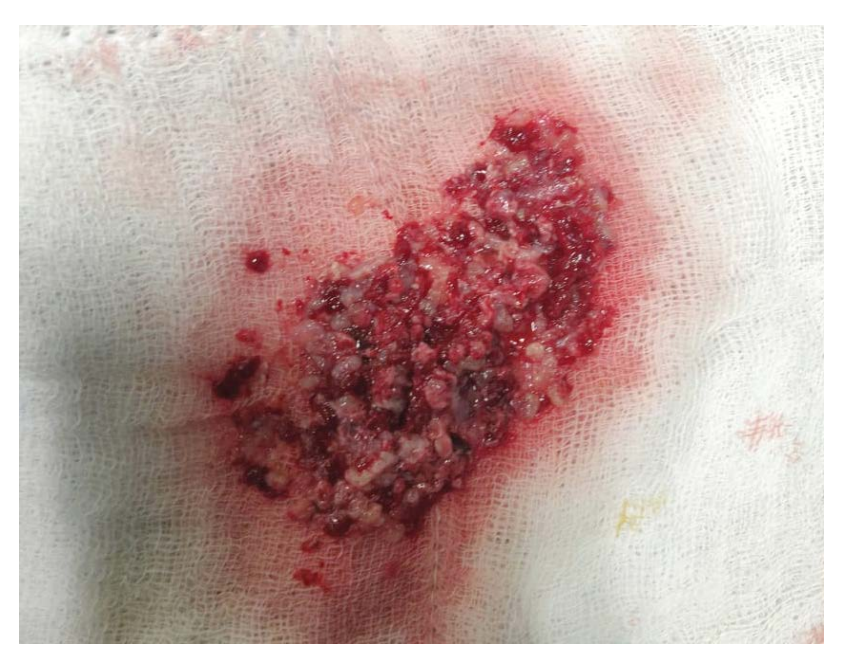

Figure 1: Adequate endometrial tissue was obtained.

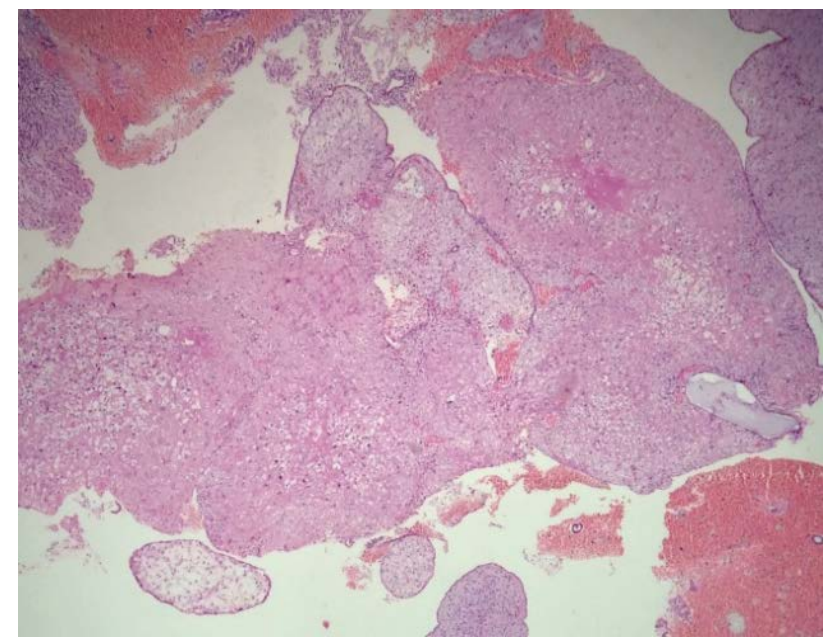

Figure 2: Placental site nodule showing degenerated intermediate trophoblastic cells surrounded by eosinophilic hyalinised stroma.
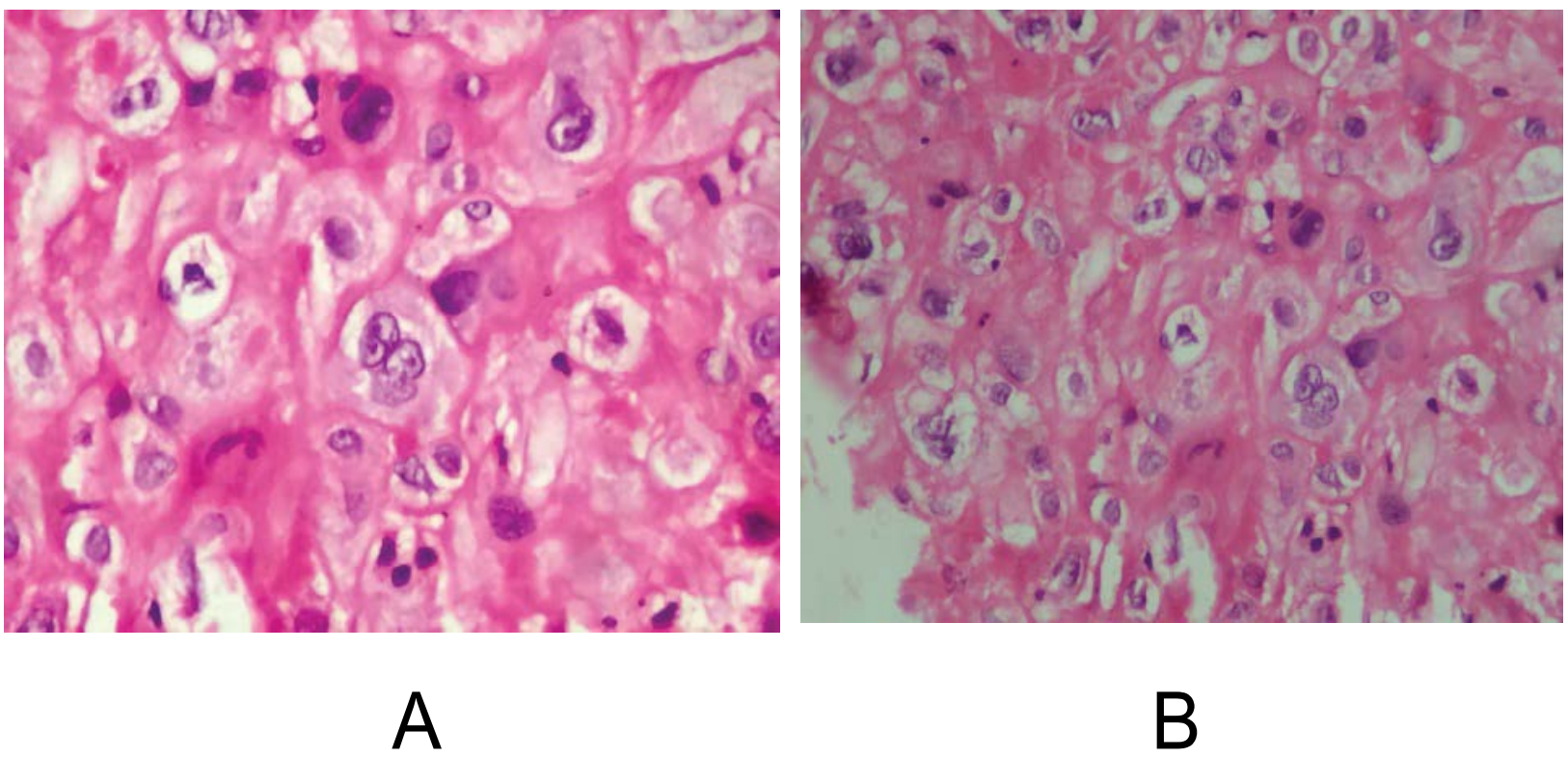

She was subjected to dilatation and curettage on day care procedure and endometrial sample was sent to histopathological analysis. After receiving the report as PILL ENDOMETRIUM with PLACENTAL SITE NODULE. She was advised for complete evacuation under anesthesia.

She underwent dilatation and curettage under spinal anesthesia and adequate endometrial tissue was obtained under ultrasound guidance which shows near complete evacuation of the residual tissue. Hysteroscopy was not available at the time of procedure (Figure 1 , Figure 2, Figure 3 and Figure 4).

\section{Treatment}

The patient underwent dilatation and curettage under anesthesia.

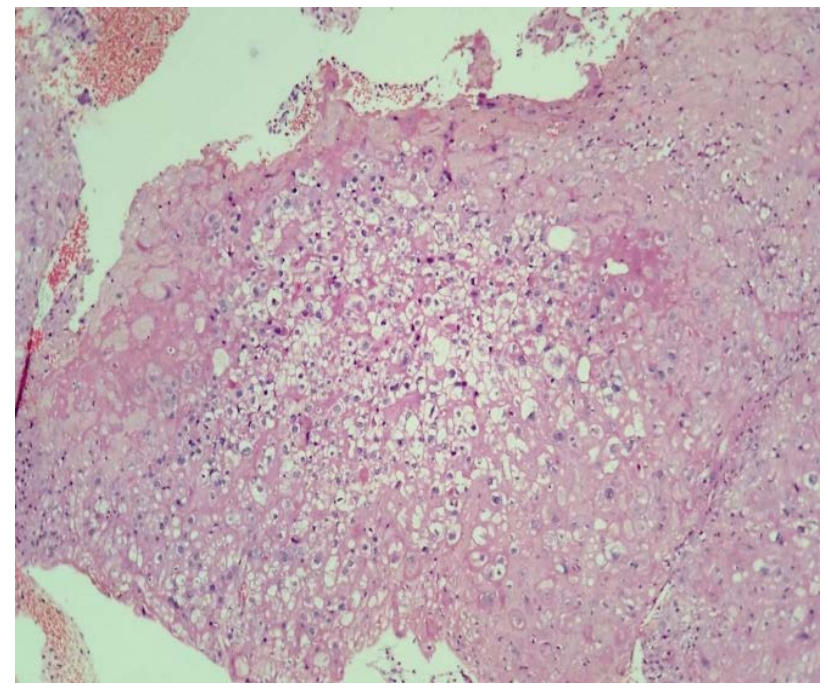

Figure 3: Well circumscribed nodules in endometrial curettings displaying focal aggregates of intermediate trophoblastic cells.

Figure 4a and Figure 4b: Intermediate trophoblastic cells have small round nucleus with clear cytoplasm, with some large cells exhibiting irregular hyperchromatic nuclei and occasional. 


\section{Follow Up}

Later followup ultrasound also showed complete resolution.

Patient had regular menstruation.

\section{Discussion}

Gestational trophoblastic disease constitutes a diverse group of lesions, which also includes neoplastic and non-neoplastic proliferations of trophoblast unaccompanied by chorionic villi [6]. A spectrum of lesions derived from the intermediate trophoblast have been described, placental site nodule or plaque, exaggerated placental site reaction, placental site trophoblastic tumor and epithelioid trophoblastic tumor $[4,6]$. Placental site nodule (PSN) represents remnants of placental site tissue that has failed to involute and may remain in the uterus for several years after the pregnancy from which it resulted. The interval from the most recent known pregnancy till the time of detection ranges widely from one month to 8 years with an average of 3 years [1]. The mean age at diagnosis is in the early thirties with the age range as broad as 20 to 49 years $[2,4]$. The clinical indications for surgical evaluation included metro-menorrhagia, hypermenorrhea, dysmenorrhea, recurrent abortions, post-coital bleeding, abnormal cervical smear, infertility etc. [1,4].

Although the overwhelming majority involve the endometrium, PSN can occasionally be seen in the cervix and rarely in the Fallopian tube and ovary [3,7-10]. PSN is generally of microscopic size but when evident grossly, it appears as yellowish or tan surface nodules in the endometrium. The size of the lesion varies from $1 \mathrm{~mm}$ to $14 \mathrm{~mm}$ with average of $2.1 \mathrm{~mm}[4,5]$. Microscopically, PSN is characterized by single or multiple, small round or ovoid, well defined extensively hyalinized eosinophilic nodules composed of cords, clusters and single cells of intermediate trophoblast. The cells are small with glycogen rich clear cytoplasm or large with abundant eosinophilic to amphophilic cytoplasm. Nuclear hyperchromatism, multinucleation and degenerative atypia are common, but mitotic figures are rarely seen $[1,4]$. Small, round eosinophilic cytoplasmic inclusions and Mallory's hyaline have been described within the trophoblastic cells $[1,11]$. PSN is a benign lesion with no evidence of recurrence requiring no specific treatment or follow up $[1,4]$.

The differential diagnosis of PSN includes other lesions of intermediate trophoblast like placental site trophoblastic tumor, epithelioid trophoblastic tumor and exaggerated placental site reaction. The small size, presence of well defined, poorly cellular hyaline nodules with paucity of mitotic figures and lack of association with current or recent pregnancy differentiate PSN from these trophoblastic lesions. PSNs are positive for placental alkaline phosphatase and negative/focally positive for Mel-CAM and $\mathrm{hpL}$ in contrast to placental site trophoblastic tumors [5,6]. Exaggerated placental site reaction is distinguished by an admixture of intermediate trophoblast and syncytiotrophoblastic cells laid out in cords and nests and by the absence of hyaline nodules. Placental site trophoblastic tumour differs from PSN by features of trophoblastic infiltration of muscle fibers and vasculotropism [12]. Nontrophoblastic lesions that may be confused with PSN include squamous cell carcinoma. Larger size, greater cytological atypia with mitosis and presence of keratinized cells are pointers towards squamous carcinoma [13]. Additionally, immunoreactivity for inhibin alpha and cytokeratin 18 and a low Ki-67 labeling index favor PSN [5]. PSN has also often been misinterpreted as hyalinized decidua. Decidual cells have more distinct cell membranes, basophilic cytoplasm and pale, uniform nuclei in contrast to the amphophilic or deeply eosinophilic cytoplasm and hyperchromatic, often pleomorphic nuclei of PSN. Intermediate trophoblastic cells are positive for both cytokeratin and $\mathrm{hpL}$, while decidual cells are negative [1].

Treatment depends on the age of presentation as this patient was young, conservative management was done patient is on regular follow up and she is having normal regular cycles. However, hysterectomy can be considered the modality of treatment in cases where there is no relief of symptoms on conservative management.

To conclude, PSN may have bizarre histologic features necessitating differentiation from aggressive lesions of intermediate trophoblast and from squamous cell carcinoma [13]. The lack of association with recent pregnancy compounds the problem. Here in lies the importance of this, infrequently encountered, less known benign trophoblastic lesion.

\section{Points for clinicians:}

- Placental site nodule (PSN) is an uncommon condition which should be suspected in cases of abnormal bleeding, especially following uterine surgical procedures preceding last pregnancy.

- It would be prudent to closely follow-up cases of atypical PSN.

- Even in the presence of a history of previous irregular cycles, a patient presenting with worsening menstrual problems, especially after an intercurrent pregnancy, should be thoroughly investigated to look for other causes.

- PSN can present remotely from the preceding pregnancy.

\section{Authors Declarations}

Source of support: Nil.

Conflict of interest: None declared.

Patient consent obtained. 


\section{References}

1. Young RH, Kurman RJ, Scully RE (1990) Placental site nodules and plaques: A clinicopathologic analysis of 20 cases. Am J Surg Pathol 4: 1001-1009.

2. Huettner PC, Gersell DJ (1994) Placental site nodule: A clinicopathologic study of 38 cases. Int J Gynecol Pathol 13: 191-198.

3. Pramanick A, Hwang WS, Mathur M (2014) Placental site nodule (PSN): An uncommon diagnosis with a common presentation. Case Reports.

4. Shih IM, Seidman JD, Kurman RJ (1999) Placental site nodule and characterization of distinctive types of intermediate trophoblast. Hum Pathol 30: 687-694.

5. Shih IM, Kurman RJ (2001) The pathology of intermediate trophoblastic tumors and tumor-like lesions. Int J Gynecol Pathol 20: 31-47.

6. Kurman RJ (1991) The morphology, biology and pathology of intermediate trophoblast: A look back to the present. Hum Pathol 22: 847-855.
7. Van Dorpe J, Moerman P (1996) Placental site nodule of the uterine cervix. Histopathology 29: 379-382.

8. Nayer R, Snell J, Silverberg S, Wong LC (1996) Placental site nodule occurring in a fallopian tube. Hum Pathol 27: 1243-1245.

9. Campello TR, Fittipaldi H, O'Valle F, Carvia RE, Noglaes FF (1998) Extrauterine (tubal) placental site nodule. Histopathology 32: 562-565.

10. Al-Hussaini M, Lioe TF, Mc Cluggage WG (2002) Placental site nodule of the ovary. Histopathology 41: 471-472.

11. Tsang WY, Chum NP, Tang SK, Tse CC, Chan JK (1993) Mallory's bodies in placental site nodule. Arch Pathol Lab Med 17: 547-550.

12. Lage JM (2002) Gestational trophoblastic diseases. In: Robboy SJ, Anderson MC, Russell P, Pathology of the female reproductive tract. ( $1^{\text {st }}$ edn), Churchill Livingstone Company, London.

13. Shastry S (2015) Placental site nodule: A tumor like trophoblastic lesion - rare case report. Med J DY Patil Univ 8: 111-113. 